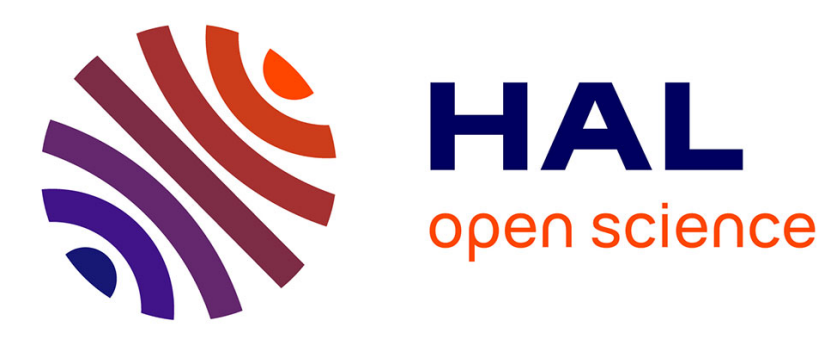

\title{
Effect of Branching on Two-Photon Absorption in Triphenylbenzene Derivatives
}

Francescca Terenziani, Céline Le Droumaguet, Claudine Katan, Olivier Mongin, Mireille Blanchard-Desce

\section{- To cite this version:}

Francescca Terenziani, Céline Le Droumaguet, Claudine Katan, Olivier Mongin, Mireille BlanchardDesce. Effect of Branching on Two-Photon Absorption in Triphenylbenzene Derivatives. ChemPhysChem, 2007, 8 (5), pp.723-734. 10.1002/cphc.200600689 . hal-00516956

\section{HAL Id: hal-00516956 https://hal.science/hal-00516956}

Submitted on 15 Sep 2010

HAL is a multi-disciplinary open access archive for the deposit and dissemination of scientific research documents, whether they are published or not. The documents may come from teaching and research institutions in France or abroad, or from public or private research centers.
L'archive ouverte pluridisciplinaire HAL, est destinée au dépôt et à la diffusion de documents scientifiques de niveau recherche, publiés ou non, émanant des établissements d'enseignement et de recherche français ou étrangers, des laboratoires publics ou privés. 
article

((M. Blanchard-Desce et al.))

((running title))

\section{Effect of Branching on Two-Photon Absorption: the Case of Triphenylbenzene Derivatives}

Dr. Francesca Terenziani, ${ }^{[\mathrm{a}] \mathrm{b}]}$ Céline Le Droumaguet, ${ }^{[\mathrm{a}]}$ Dr. Claudine Katan, ${ }^{[\mathrm{a}]}$ Dr. Olivier Mongin, ${ }^{[\mathrm{a}]}$ Dr. Mireille Blanchard-Desce* ${ }^{[\mathrm{a}]}$

((Dedicated to $))$

[a] Synthèse et ElectroSynthèse Organiques (CNRS, UMR 6510), Université de Rennes 1, Institut de Chimie, Campus Scientifique de Beaulieu, Bât 10A, F-35042 Rennes Cedex, France Fax: (+)33 (2) 23236277

E-mail: mireille.blanchard-desce@univ-rennes1.fr

[b] Dipartimento di Chimica GIAF, Università di Parma, Parco Area delle Scienze 17/A, 43100 Parma, Italy

$<$ pict $>$ Supporting information for this article is available on the WWW under http://www.chemphyschem.org or from the author.

((Suggestion for the table-of-contents text))

The two-photon absorption (TPA) cross sections of octupolar branched compounds and corresponding dipolar branches are measured by varying the nature of the end-groups (donor versus acceptors) and the length of the branches. A correlation is found between the fluorescence solvatochromic behavior and the TPA cross section, ascribed to the intramolecular charge-transfer character of the transitions. 
Keywords: charge transfer - chromophores - solvatochromism - two-photon absorption electronic coupling.

The photophysical and linear and nonlinear spectral properties of octupolar compounds with a triphenylbenzene core motif are investigated and compared with properties of corresponding dipolar branches. A correlation is found between the solvatochromic behavior and the two-photon absorption cross section. Moreover, the nature of the core is found to be responsible for the nature of the coupling between branches: in the studied case only (weak) electrostatic interactions are effective, while other cores, like the triphenylamine moiety, are able to promote coherent coupling between the branches, leading to strongly non-additive properties.

\section{Introduction}

Molecular two-photon absorption (TPA) has attracted a lot of interest over recent years both from theoretical and practical points of view. Various applications include spectroscopy, ${ }^{[1]}$ three-dimensional optical data storage, ${ }^{[2]}$ microfabrication, ${ }^{[3]}$ laser upconversion, ${ }^{[4]}$ high-resolution 3-dimensional imaging of biological systems, ${ }^{[5]}$ and photodynamic therapy. ${ }^{[6]}$ Using a two-photon excitation process (i.e. a nonlinear process involving the simultaneous absorption of two photons) instead of a conventional one-photon excitation offers a number of advantages. These include the ability for a highly confined excitation (and intrinsic three-dimensional resolution) and increased penetration depth by replacing typical one-photon excitation in the UV-visible blue region by two-photonexcitation in the visible red-near IR region, owing in particular to the reduction of scattering losses. Most of these applications require the design of compounds displaying high TPA cross-sections in order to significantly decrease the excitation intensity and provide improved excitation selectivity. This goal has stimulated the study of a variety of chromophores ranging from dipolar ${ }^{[7]}$ to quadrupolar, ${ }^{[8-10]}$ octupolar, ${ }^{[8,10-19]}$ multipolar and branched structures including dendrimers. ${ }^{[15,18,20]}$ 
A number of factors influence the TPA magnitude, among which electronic delocalization and intramolecular charge transfer (ICT) phenomena play an important role. ${ }^{[14]}$ This is a critical issue in the case of branched systems where interbranch coupling plays a major role. Several structural parameters are expected to influence this coupling such as the nature of the branches, of the core, node and peripheral moieties. Given the huge synthetic effort needed to build such structures, detailed understanding of the effect of branching of molecular entities on the linear and nonlinear optical properties is of major interest. Among the many questions that are currently debated, coherent coupling between the arms (building blocks) is of particular interest. This has prompted several recent theoretical and experimental studies using different techniques. ${ }^{[18,19,21]}$ Depending on the nature of this coupling, the ground or the excited state may be either localized or delocalized and specific optical properties - including TPA - may be either enhanced or suppressed. ${ }^{[18]}$ In recent work, we have shown that branched systems based on the assembly of dipolar chromophores via a common triphenylamine core give rise to a sizeable electronic coupling between branches. ${ }^{[10]}$ The interaction between branched chromophores is responsible for splitting between degenerate excited states, so that the amount of coupling can be extracted within the Frenkel exciton scheme. A concerted multidimensional ICT takes place from the central electrondonating moiety to the electron-withdrawing periphery upon excitation and the inter-branch electronic coupling gives rise to major TPA enhancement. A breakage of the coherent coupling between the arms is observed after excitation which then localizes on one of the branches, prior to emission, leading to highly dipolar emitting excited states. ${ }^{[10,22],[17]}$

The aim of this paper is to investigate how the photophysical and TPA properties can be modified by playing on the nature of the coupling core moiety. In that perspective we have studied a series of branched systems where dipolar units are connected via a common triphenylbenzene core (Figure 1). Such three-branched systems, bearing either strong electron-donating or electron-withdrawing groups were previously shown to allow either periphery-to-core or core-to-periphery multidimensional charge transfer leading to large first hyperpolarizabilities (i.e. second-order optical response). ${ }^{[16]}$ Earlier structure-property studies carried out on different series of octupolar molecules showed that such ICT phenomena can 
lead to large TPA cross-sections. ${ }^{[12,13,23]}$ These features prompt us to investigate the TPA properties of a series of octupolar derivatives built from a triphenylbenzene core in correlation with the ICT process. The ability of the triphenylbenzene core to promote electronic coupling between branches and possibly lead to enhanced TPA is investigated by comparing the photophysical and TPA properties of the three-branched systems (octupolar compounds TPB $\left[(\mathbf{P V})_{1} \mathbf{N H e x}_{2}\right]_{3}$ and $\left.\mathbf{T P B}\left[(\mathbf{P V})_{1} \mathbf{S O}_{2} \mathbf{C F}_{3}\right]_{3}\right)$ with those of their dipolar counterparts where the triphenylbenzene (TPB) core has been replaced by a biphenyl (BP) moiety $\left(\mathbf{B P}(\mathbf{P V})_{1} \mathbf{N H e x}_{2}\right.$ and $\left.\mathbf{B P}(\mathbf{P V})_{1} \mathbf{S O}_{2} \mathbf{C F}_{3}\right)$. In addition, the effect of the nature of the peripheral groups (donor versus acceptor) and of the length of the conjugated arms $\left(\mathbf{T P B}\left[(\mathbf{P V})_{2} \mathbf{N H e x}_{2}\right]_{3}\right.$ versus $\left.\left.\mathbf{T P B}\left[(\mathbf{P V})_{1} \mathbf{N H e x}_{2}\right)\right]_{3}\right)$ on TPA responses is investigated. Moreover, the solvatochromic behavior of these systems is addressed in order to characterize the nature of the emitting excited state and assess the ICT.

\section{Results and Discussion}

\section{Molecular geometry}

Octupolar three-branched molecules derived from the TPB core adopt a propellershape conformation (Figure 2) where the three phenyl substituents on the central phenyl unit are twisted by about $45^{\circ}$. Interestingly, the ground-state optimized geometry of $\mathbf{B P}(\mathbf{P V})_{\mathbf{1}} \mathbf{N H e x}_{\mathbf{2}}$ can be superposed to that of one branch of $\mathbf{T P B}\left[(\mathbf{P V})_{\mathbf{1}} \mathbf{N H e x}_{2}\right]_{3}$ showing identical geometrical parameters except for a small dissymmetry at the terminal phenyl ring of BP (Figure 3A). This suggests that the three branches behave as nearly independent subchromophores. The nitrogen atom is slightly out of plane and the twist angle between the two phenyl rings of $\mathbf{B P}$ is about $45^{\circ}$ while that between the two phenyl rings on each side of the double bond is closer to $40^{\circ}$. $\mathbf{B P}(\mathbf{P V})_{1} \mathbf{S O}_{2} \mathbf{C F}_{3}$ shows similar geometrical parameters with respectively slightly reduced and increased twist angles, and the terminal $\mathbf{C F}_{\mathbf{3}}$ almost perpendicular to the molecular backbone (Figure 3B). The bond-length alternation (BLA) parameter, defined as the difference between single and double bonds in the vinyl bridge, is $0.15 \AA$ for all chromophores in the ground state. This parameter reflects the low degree of 
charge transfer in the ground state. This is confirmed by the large value of the ${ }^{1} \mathrm{H}-{ }^{1} \mathrm{H}$ coupling constant $(\approx 16.5 \mathrm{~Hz})$ in the vinylic bond of compounds $\mathbf{B P}(\mathbf{P V})_{\mathbf{1}} \mathbf{N H e x}_{\mathbf{2}}$ and $\mathbf{B P}(\mathbf{P V})_{\mathbf{1}} \mathbf{S O}_{\mathbf{2}} \mathbf{C F}_{\mathbf{3}}$ in solution, indicative of a full double bond character.

Excited-state geometry optimization of $\mathbf{B P}(\mathbf{P V})_{\mathbf{1}} \mathbf{N H e x}_{\mathbf{2}}$ leads to an almost planar molecule: carbons bonded to nitrogen and nitrogen itself are in the same plane, as well as adjacent phenyl and phenylene-vinylene moieties. BP shows a reduced twist angle of about $25^{\circ}$ (Figure 3A). A similar planarization of the excited state is observed for $\mathbf{B P}(\mathbf{P V})_{\mathbf{1}} \mathbf{S O}_{\mathbf{2}} \mathbf{C F}_{\mathbf{3}}$ (Figure 3B). This change of geometry is associated to a vanishing BLA, which indicates that the electronic delocalization significantly increases in the emitting excited state.

\section{Spectroscopic investigations}

Photophysical properties. The absorption and fluorescence properties of dipolar and octupolar derivatives are collected in Table 1. All compounds show an intense absorption band in the near-UV region and emission in the visible region. A net bathochromic and hyperchromic shift of the absorption band is observed both for dipolar and octupolar chromophores bearing electron-donating end-groups as compared to their counterparts bearing electron-withdrawing end-groups (Figure 4). The donor derivatives also show significantly red-shifted emission and much larger fluorescence quantum yields (Table 1). At opposite, the acceptor derivatives display larger Stokes-shifts, indicative of a more pronounced nuclear reorganization after absorption prior to emission.

As shown in Figure 5, the absorption spectra of the octupolar derivatives are slightly red-shifted as compared to those of their dipolar analogues. The slight red-shift (about 0.04$0.05 \mathrm{eV}$ in toluene) indicates that only weak coupling between the branches occurs in triphenylbenzene derivatives. This suggests that the branches behave as nearly independent subchromophores in the ground state, as suggested by the calculated ground state geometries. Such conclusion was also derived from recent Hyper-Raman studies conducted on other octupolar derivatives built from a TPB core. ${ }^{[24]}$ The quasi-proportionality of the molar extinction coefficient with respect to the number of branches further corroborates this analysis 
(Table 1). It should be stressed however that the coupling (as measured by the red-shift of the absorption band) increases with increasing solvent polarity (Figure 5). This indicates that the coupling between the dipolar branches slightly increases in polar environments, as due to increased polarity and polarization of the dipolar branches in response to the solvation interaction.

In low-polarity solvents (where the coupling between branches is vanishing), we observe that branching causes a noticeable enhancement of the fluorescent quantum yield, in correlation with a definite increase of the radiative decay rate (Table 1). Indeed the radiative lifetime of the three-branched octupoles are significantly shorter than that of the corresponding dipolar branches. Such behavior contrasts with what was observed for octupolar derivatives with similar branches based on the triphenylamine core. ${ }^{[10]}$ This behavior suggests that a certain degree of delocalization is occurring in the relaxed excited state of the three-branched systems having a TPB core, leading to larger transition dipole moments and thus shorter radiative lifetimes than analogous dipolar derivatives with a $\mathbf{B P}$ moiety. ${ }^{[25]}$ Indeed calculations conducted on the dipolar analogue bearing a TPB terminal moiety instead of a BP moiety $\left(\mathbf{T P B}\left[(\mathbf{P V})_{1} \mathbf{N H e x}_{2}\right]_{3}\right)$ predict larger transition dipole moment (Table 2). This suggests that the TPB core is involved in the delocalization process in the case of three-branched derivatives, explaining the difference in radiative lifetimes.

In the case of three-branched derivatives bearing donor end-groups, the radiative decay rate can be further enhanced by increasing the length of the branches (Table 1). This increase cannot be accounted for only on the basis of the increase in molar absorption coefficient (i.e. oscillator strength), ${ }^{[25]}$ and indicates that the transition dipole of the emitting state is significantly enhanced as compared to that of the ground state. This suggests that the planarization process and reduction of BLA in the conjugated branch is also operative for the elongated three-branched system and extends over the full length of the conjugated branch, leading to an increase of the transition dipole in the emitting state. Indeed, such an increase of transition dipole moments is also predicted by calculations for the dipolar derivatives (see Table 2). 
Interestingly, in the case of donor derivatives, a decrease of the non-radiative decay rate is also observed for three-branched derivatives. The combination of these effects leads to a significant increase in the fluorescence quantum yield, the longest three-branched molecule having by far the largest fluorescence quantum yield in the series. The lengthening of the branches also produces a significant bathochromic shift of both the absorption and emission bands (Table 1).

Solvatochromism. Both three-branched octupolar and dipolar chromophores show a definite positive solvatochromic behavior. As illustrated in Figure 6, increasing solvent polarity induces a slight red-shift of the absorption band and a marked bathochromic shift of the emission band. In the case of dipolar systems, such behavior is typical of an ICT transition with an increase of dipole moment upon excitation. Indeed, transition orbitals calculations (Figure 3) confirm that a definite charge transfer from the biphenyl terminal group to the acceptor end-group occurs in $\mathbf{B P}(\mathbf{P V})_{1} \mathbf{S O}_{2} \mathbf{C F}_{3}$ upon excitation, whereas a charge transfer from the donor end-group to the biphenyl terminal group occurs in $\mathbf{B P}(\mathbf{P V})_{\mathbf{1}} \mathbf{N H e x _ { 2 }}$. This is correlated with the reduced BLA obtained in the excited state as compared to the ground state. In the emitting excited state, the conjugated system becomes almost planar and the BLA vanishes. Such phenomenon has already been observed in other conjugated systems such as conjugated polymers. ${ }^{[26]}$

As a consequence of this charge transfer phenomena, both molecules have a higher dipole moment in the excited state (Table 2). As shown in Figure 7, the solvatochromic behavior of both dipolar chromophores can be fitted with a Lippert-Mataga relationship: ${ }^{[27]}$

$$
\tilde{v}_{a b s}-\tilde{v}_{e m}=2 \Delta \mu_{e f f}^{2} \Delta f /\left(h c a^{3}\right)+\text { const }
$$

where $\tilde{V}_{a b s}\left(\tilde{V}_{e m}\right)$ is the wavenumber of the absorption (fluorescence) maximum, $h$ is the Planck constant, $c$ is the light velocity, $a$ is the radius of the solute spherical cavity, and $\Delta f=$ $(\varepsilon-1) /(2 \varepsilon+1)-\left(n^{2}-1\right) /\left(2 n^{2}+1\right)$, where $\varepsilon$ is the dielectric constant and $n$ is the refractive index of the solvent. In the simple case where the Franck-Condon and relaxed excited state dipoles are identical (as well as relaxed and Franck-Condon ground state dipoles), $\Delta \mu_{\text {eff }}$ 
simply corresponds to $\left(\mu_{E}-\mu_{G}\right), \mu_{G}$ and $\mu_{E}$ being the ground-state and excited-state dipole moments. More generally,

$$
\Delta \mu_{e f f}^{2}=\mu_{E}^{(f)}\left(\mu_{E}^{(f)}-\mu_{G}^{(f)}\right)-\mu_{G}\left(\mu_{E}-\mu_{G}\right)
$$

where the $(f)$ superscript indicates the equilibrium excited-state geometry (relevant to fluorescence). In the present study, calculations show that $\mu_{E}$ and $\mu_{G}$ are pretty sensitive to geometrical changes occurring between absorption and emission processes (Table 2), so that the exact expression in (3) is for sure safer to be used.

We observe that the solvatochromic behavior of octupolar chromophores can also be fitted with a Lippert-Mataga relationship (Figure 7). This is a strong evidence that the emission process occurs from a dipolar excited state. The slope values are smaller for threebranched octupoles as compared to their dipolar counterparts (Figure 7 and Table 1). The dipolar nature of the emitting excited state clearly indicates that excitation localizes, prior to emission, on one of the dipolar branches, as already observed for triphenylamine-based multibranched structures. ${ }^{[10,22]}$ Nevertheless, the smaller value of the Lippert-Mataga slope with respect to dipolar analogues suggests that this phenomenon of localization is not complete, as also previously guessed from lifetime values.

Dipolar and octupolar chromophores bearing donor end-groups show a more pronounced solvatochromic behavior (larger slope values) as compared to those bearing acceptor end-groups. This is indicative of either a more pronounced charge transfer (i.e. larger $\Delta \mu_{e f f}$ values) or smaller cavities for derivatives with donor end-group as compared to those with acceptor end-groups. By estimating the cavity volume to about $300 \AA^{3}$, a $\Delta \mu_{\text {eff }}$ of $7 \mathrm{D}$ is derived for chromophore $\mathbf{B P}(\mathbf{P V})_{\mathbf{1}} \mathbf{N H e x}_{2}$ and $6 \mathrm{D}$ for chromophore $\mathbf{B P}(\mathbf{P V})_{\mathbf{1}} \mathbf{S O}_{\mathbf{2}} \mathbf{C F}_{3}$ from the solvatochromic slopes. Calculated values in Table 2 lead to comparable results when using expression (3). Similar values can be derived for the corresponding octupolar threebranched systems $\mathbf{T P B}\left[(\mathbf{P V})_{1} \mathbf{N H e x}_{2}\right]_{3}$ and $\mathbf{T P B}\left[(\mathbf{P V})_{1} \mathbf{S O}_{2} \mathbf{C F}_{3}\right]_{3}$. The more pronounced charge transfer for molecules with donor end-groups as compared to that of acceptor endgroups correlates with the bathrochromic and hyperchromic shift of the absorption band and 
suggest that both dipolar and octupolar derivatives bearing donor end-groups may lead to larger TPA cross-section. ${ }^{[13]}$

The longest three-branched derivative with donor end-groups show an even more pronounced solvatochromism (Figure 7) although the cavity radius is significantly increased. Indeed this suggests that the ICT is still operative along the total length of the branch in $\mathbf{T P B}\left[(\mathbf{P V})_{2} \mathbf{N H e x}_{2}\right]_{3}$, leading to a very large relaxed excited-state dipole. The enhancement of $\Delta \mu_{\text {eff }}$, in addition to the hyperchromic and bathochromic shift induced by the increase of the length of the branch, is expected to lead to significant enhancement of TPA.

Two-photon absorption. Wavelength-dependent TPA cross sections are shown in Figures 8 and 9 (normalized per branch) and main characteristics are summarized in Table 3. Figure 8 clearly shows that the TPA response is nearly additive with respect to the number of branches: indeed TPA cross sections normalized per branch are very similar for octupoles and corresponding dipoles. This is a further confirmation of the almost independency of each branch in octupolar compounds based on the triphenylbenzene central core, corresponding to weak (almost vanishing) electronic coupling. This result is markedly different from that obtained for structures based on a triphenylamine central core, where a strong non-additivity was found for quadrupolar and octupolar branched structures with respect to the dipolar branch. ${ }^{[10,22]}$ So, while triphenylamine is able to promote sizeable electronic coupling between branches, triphenylbenzene is not. While in triphenylamine-based branched structures the coupling leads to mixing of single-branch excited states, in triphenylbenzene-based structures each branch is almost unperturbed by other branches, so that properties are nearly additive. The different behavior of the two series (triphenylamine-based and triphenylbenzene-based) gives important hints on the nature of the coupling between branches. Indeed, if coupling was only due to electrostatic interactions between the transition dipole moments of the branches (Frenkel-exciton model), ${ }^{[28]}$ the strength of the coupling should be comparable in the two series (since transition dipole moments are comparable). But this is not the case, indicating that other sources of coupling are needed to explain the behavior of the triphenylamine-based series. Indeed, the need of interactions beyond the Frenkel-exciton model was already 
suggested in Ref. ${ }^{[10]}$ in order to explain the strong enhancement of TPA cross sections as a consequence of branching. As a matter of fact, the simple excitonic model was not able to reproduce this enhancement, while more refined quantum chemical calculations did. This observation suggested that not only dipolar interactions but also coherent interactions were important in defining the total coupling and hence the spectroscopic properties of branched structures. ${ }^{[10]}$ While triphenylamine has been proved to be able to promote this kind of coupling, results presented here allow to conclude that the triphenylbenzene core is not.

The end-group effect on the TPA activity deserves some comments. Compounds with donor end-groups display higher TPA cross sections than corresponding structures with acceptor end-groups (Table 3). Even if (for solubility reasons) measurements have been carried out in different solvents for donors and acceptors (toluene for donors and DMSO for acceptors), the observed increase for donor-based compound is reliable. In fact, the effect of changing solvent polarity can be evaluated by means of the linear absorption spectra: only a very weak shift is observed when going from toluene to DMSO, accompanied by a slight broadening of the band and slight increase of the molar extinction coefficient on the maximum (of the order of 10\%). This means that the oscillator strength slightly increases with increasing solvent polarity, due to the increase of the transition dipole moment (the molecule is polarizable so that its properties depend on environmental parameters). Despite the polar solvent DMSO favors an increased transition dipole with respect to toluene, compounds with acceptor end-groups (dissolved in DMSO) have lower TPA cross sections $\left(\sigma_{2}\right)$ than corresponding compounds with donor end-groups (dissolved in toluene). This means that this behavior is not linked to the particular choice of solvents. This trend can be actually confirmed by the $\sigma_{2}$ values obtained through a two-state model, starting from calculated dipole moments (Table 2). In fact, for dipolar molecules the TPA cross section can easily be expressed by the aid of a two-state model:

$$
\sigma_{2}=0.002076 \mu_{e g}^{2}\left(\mu_{E}-\mu_{G}\right)^{2} / \Gamma
$$

where $\sigma_{2}$ is obtained in GM $\left(10^{-50} \mathrm{~cm}^{4}\right.$.s.photon $\left.{ }^{-1}\right)$ when transition and state dipole moments are used in $\mathrm{D}$ and the half-bandwidth at half maximum $\Gamma$ in $\mathrm{eV}$. Thus, $\sigma_{2}$ is proportional to the 
product of the squared transition dipole moment and the squared difference between excitedstate and ground-state dipole moments $\left(\mu_{E}-\mu_{G}\right)$. Data in Table 1 suggest that the increased $\sigma_{2}$ of $\mathbf{B P}(\mathbf{P V})_{1} \mathbf{N H e x}_{2}$ with respect to $\mathbf{B P}(\mathbf{P V})_{1} \mathbf{S O}_{\mathbf{2}} \mathbf{C F}_{3}$ is due only for one half to the increased transition dipole moment, while the further increase must be linked to the increased $\left(\mu_{E}-\mu_{G}\right)$ value. This is confirmed by the more pronounced solvatochromic behavior of $\mathbf{B P}(\mathbf{P V})_{1} \mathbf{N H e x}_{2}$, as described by the slope values in Table 1 . Indeed, while the solvatochromic slope is proportional to $\Delta \mu_{e f f}^{2}$ and the TPA cross section to $\left(\mu_{E}-\mu_{G}\right)^{2}$, it is reasonable to suppose that these two quantities behave very similarly.

For octupolar structures the behavior is similar, the compound having donor endgroups displaying higher TPA cross section than the analogous compound with acceptor endgroups. This is naturally explained on the basis of results for corresponding dipoles, since all data demonstrate that branches in octupolar structures behave as nearly independent subchromophores.

The longest compound, $\mathbf{T P B}\left[(\mathbf{P V})_{2} \mathbf{N H e x}_{2}\right]_{3}$, has by far the highest TPA cross section among all the studied structures (doubled with respect to the shorter analogue). This is in agreement with predictions based on photophysical data. In fact, not only the transition dipole moment is increased with respect to the shorter analogue, but also the ICT from the donor end-groups to the central core upon excitation is more pronounced, as demonstrated by the much stronger solvatochromic behavior. Indeed, while the increase of oscillator strength can only account for $\sim 20 \%$ (see Table 1) of the total enhancement of the TPA response, the increased ICT is responsible for most of the observed enhancement. Actually, for chromophores derived from the TPB core, a correlation between the solvatochromic magnitude and the peak TPA response of lowest energy is observed (Figure 10). This provides an interesting way to evaluate the TPA response of other derivatives built from the TPB core. 


\section{Conclusions}

In this paper we presented a study of the photophysical and TPA properties of octupolar three-branched systems based on the triphenylbenzene core and corresponding dipolar systems with a biphenyl motif (branches). Compounds bearing donor and acceptor end-groups were synthesized and investigated. The lowest-energy electronic transition corresponds in all cases to a strong ICT from the triphenylbenzene or biphenyl motif towards the acceptor end-groups or vice versa in the case of donor end-groups. This charge transfer character is more pronounced in the case of donor end-groups, as revealed by the stronger solvatochromic behavior of fluorescence spectra with respect to corresponding compounds with acceptor end-groups.

All spectral properties indicate that the three branches in octupolar compounds behave nearly independently: only small deviations from the additive behavior are observed in fluorescence, absorption and TPA spectra when comparing the octupolar systems with the corresponding dipolar branches. A clear indication of localization of the excitation on one branch in octupolar compounds prior to emission is given by the strong fluorescence solvatochromism, only slightly reduced with respect to the corresponding dipoles. This slight effect is probably due to a certain degree of delocalization occurring in the relaxed excited state of the three-branched systems, as also suggested by excited-state lifetimes.

The comparison of results presented here with results on analogous compounds based on a triphenylamine central core ${ }^{[10,22]}$ allows to identify the nature of the coupling between branches in these and other octupolar branched systems. In fact, at difference with respect to the present compounds, analogous triphenylamine-based systems were characterized by strongly non-additive properties. This different behavior is observed despite the comparable values of transition dipole moments, and hence comparable values of the electronic coupling due to electrostatic interactions (Frenkel-exciton model). The comparison allows then to conclude that, while in branched systems based on the triphenylbenzene core only electrostatic interactions contribute to the electronic coupling between branches, in the case of the triphenylamine core other sources of coupling are present, such as coherent interactions. 
We also show that a correlation exists between the solvatochromic behavior and the TPA cross section of these compounds, as due to the ICT character of the transitions. This is true not only inside the investigated series, but also with respect to analogous systems based on the triphenylamine central core. ${ }^{[17,22]}$ In fact, triphenylamine-based compounds having the same branches as presented here show a more pronounced solvatochromic behavior and corresponding higher TPA cross sections. ${ }^{[17,22]}$ Hence results presented here, together with results on analogous series allow to conclude that the study of the solvatochromic behavior gives an estimation of the relative TPA cross section for systems built from phenylenevinylene branches and dominated by the ICT phenomenon upon excitation.

\section{Experimental Section}

\section{Chemicals}

Octupolar compounds TPB $\left[(\mathbf{P V})_{1} \mathbf{N H e x}_{2}\right]_{3}$ and $\mathbf{T P B}\left[(\mathbf{P V})_{2} \mathbf{N H e x}_{2}\right]_{3}$ were prepared according to litterature. ${ }^{[16]}$ Their dipolar analogue $\mathbf{B P}(\mathbf{P V})_{1} \mathbf{N H e x}_{2}$ was obtained as a pure $E$ compound from the

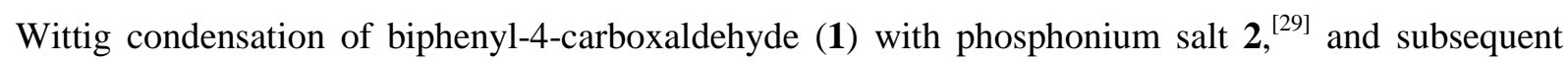
isomerization of the obtained mixture of stereoisomers using a catalytic amount of iodine under illumination (Scheme 1). A similar methodology did not afford $\mathbf{B P}(\mathbf{P V})_{1} \mathbf{S O}_{2} \mathbf{C F} \mathbf{F}_{3}$ as a pure $E$ isomer. Its synthesis was therefore achieved by means of the Heck coupling of 4-ethenyl-1,1'-biphenyl ${ }^{[30]}(\mathbf{3})$ with bromo derivative 4. Octupolar compound $\mathbf{T P B}\left[(\mathbf{P V})_{1} \mathbf{S O}_{2} \mathbf{C F}_{3}\right]_{3}$ was prepared analogously via the threefold Heck coupling of trivinyl $\mathbf{6}$ (obtained from the condensation of trialdehyde $\mathbf{5}^{[16]}$ and methyltriphenylphosphonium iodide) with three equivalents of $\mathbf{4}$ (Scheme 1).

4-[(1E)-2-[1,1'-Biphenyl]-4-ylethenyl]- $N, N$-dihexylbenzenamine $\left(\mathrm{BP}(\mathrm{PV})_{1} \mathrm{NHex}_{2}\right)$. To a solution of biphenyl-4-carboxaldehyde (1) (0.500 g, $2.74 \mathrm{mmol})$ and phosphonium salt $\mathbf{2}^{[29]}$ (2.37 g, $\left.3.57 \mathrm{mmol}\right)$ in anhydrous $\mathrm{CH}_{2} \mathrm{Cl}_{2}(25 \mathrm{~mL}) t$ - $\mathrm{BuOK}(0.553 \mathrm{~g}, 4.93 \mathrm{mmol})$ was added. The mixture was stirred at 20 ${ }^{\circ} \mathrm{C}$ for $24 \mathrm{~h}$. After addition of water, extraction with $\mathrm{CH}_{2} \mathrm{Cl}_{2}$, and drying $\left(\mathrm{Na}_{2} \mathrm{SO}_{4}\right)$, the solvent was evaporated. The residue was purified by filtration through a short pad of silica gel (heptane/ $\mathrm{CH}_{2} \mathrm{Cl}_{2}$ 50:50), to afford a mixture of isomers, which was dissolved in $\mathrm{Et}_{2} \mathrm{O}(18 \mathrm{~mL})$. A catalytic amount of $\mathrm{I}_{2}$ $(0.4 \%)$ was then added and the solution was stirred at $20{ }^{\circ} \mathrm{C}$ for $8 \mathrm{~h}$ under light exposure (60 W lamp). 
The organic layer was washed with aqueous $\mathrm{Na}_{2} \mathrm{~S}_{2} \mathrm{O}_{3}$ and dried $\left(\mathrm{Na}_{2} \mathrm{SO}_{4}\right)$. After evaporation of the solvent, the raw product was purified by column chromatography (heptane/ $\mathrm{CH}_{2} \mathrm{Cl}_{2}$ 85:15) to yield $0.990 \mathrm{~g}(82 \%)$ of $\mathbf{B P}(\mathbf{P V})_{1} \mathbf{N H e x}_{2} ;{ }^{1} \mathrm{H}$ NMR $\left(200.13 \mathrm{MHz}, \mathrm{CDCl}_{3}\right) \delta 7.64-7.58(\mathrm{~m}, 2 \mathrm{H}), 7.55(\mathrm{~m}, 4 \mathrm{H})$, 7.46-7.30 (m, 3H), 7.39 and $6.62\left(\mathrm{AA}^{\prime} \mathrm{XX}^{\prime}, J_{\mathrm{AX}}=8.7 \mathrm{~Hz}, 4 \mathrm{H}\right), 7.08(\mathrm{~d}, J=16.4 \mathrm{~Hz}, 1 \mathrm{H}), 6.90(\mathrm{~d}, J=$ $16.4 \mathrm{~Hz}, 1 \mathrm{H}), 3.28(\mathrm{t}, J=7.5 \mathrm{~Hz}, 4 \mathrm{H}), 1.59(\mathrm{~m}, 4 \mathrm{H}), 1.32(\mathrm{~m}, 12 \mathrm{H}), 0.91(\mathrm{~m}, 6 \mathrm{H}) ;{ }^{13} \mathrm{C}$ NMR $(75.47$ $\left.\mathrm{MHz}, \mathrm{CDCl}_{3}\right) \delta 147.8,140.8,139.0,137.4,129.0,128.7,127.8,127.1,127.0,126.7,126.3,124.4$, 123.0, 111.6, 51.0, 31.7, 27.2, 26.8, 22.7, 14.0; HRMS $\left(\mathrm{ES}^{+}, \mathrm{MeOH} / \mathrm{CH}_{2} \mathrm{Cl}_{2}\right)$ calcd for $\mathrm{C}_{32} \mathrm{H}_{42} \mathrm{~N}$ $\left([\mathrm{M}+\mathrm{H}]^{+}\right) \mathrm{m} / z$ 440.3317, found 440.3323. Anal. Calcd for $\mathrm{C}_{32} \mathrm{H}_{41} \mathrm{~N}$ (439.69): C, 87.42; H, 9.40; N, 3.19. Found: C, 87.79; H, 9.47; N, 2.92.

4-[(1E)-2-[4-[(Trifluoromethyl)sulfonyl]phenyl]ethenyl]-1,1'-biphenyl $\left(\mathrm{BP}(\mathrm{PV})_{1} \mathrm{SO}_{2} \mathrm{CF}_{3}\right)$. Air was removed from a solution of 4-ethenyl-1,1'-biphenyl ${ }^{[30]}$ (3) $(200 \mathrm{mg}, 1.109 \mathrm{mmol})$ and 1-bromo-4[(trifluoromethyl)sulfonyl]benzene (4) $(353 \mathrm{mg}, 1.22 \mathrm{mmol})$ in anhydrous DMF (5 mL) by blowing argon for $20 \mathrm{~min}$. Then triethylamine (146 mg, $1.44 \mathrm{mmol})$, tri-o-tolylphosphine (34 mg, $0.111 \mathrm{mmol})$ and palladium diacetate $(14.5 \mathrm{mg}, 0.055 \mathrm{mmol})$ were added. The mixture was stirred at $110^{\circ} \mathrm{C}$ for 15 h. The solvent was removed by distillation, and the raw product was purified by column chromatography (heptane/ $\mathrm{CH}_{2} \mathrm{Cl}_{2} 30: 70$ ) to yield $311 \mathrm{mg}$ (72\%) of $\mathbf{B P}(\mathbf{P V})_{1} \mathbf{S O}_{2} \mathbf{C F}_{3}$ as a pale yellow solid; ${ }^{1} \mathrm{H}$ NMR (200.13 MHz, $\left.\mathrm{CDCl}_{3}\right) \delta 8.01$ and $7.76\left(\mathrm{AA}^{\prime} \mathrm{XX}\right.$ ', $\left.J_{\mathrm{AX}}=8.5 \mathrm{~Hz}, 4 \mathrm{H}\right), 7.64-7.61(\mathrm{~m}$, 6H), $7.46(\mathrm{~m}, 1 \mathrm{H}), 7.43(\mathrm{~d}, J=7.5 \mathrm{~Hz}, 2 \mathrm{H}), 7.37(\mathrm{~d}, J=16.3 \mathrm{~Hz}, 1 \mathrm{H}), 7.18(\mathrm{~d}, \mathrm{~J}=16.3 \mathrm{~Hz}, 1 \mathrm{H}) ;{ }^{13} \mathrm{C}$ NMR $\left(75.47 \mathrm{MHz}, \mathrm{CDCl}_{3}\right) \delta 145.8,141.9,140.3,134.9,134.1,131.2,128.9,127.7,127.7,127.6$, $127.5,127.4,127.0,125.9,119.9(\mathrm{q}, J=324.1 \mathrm{~Hz}) ;{ }^{19} \mathrm{~F}$ NMR $\left(282.38 \mathrm{MHz}, \mathrm{CDCl}_{3}\right) \delta-78.41 ; \mathrm{HRMS}$ (EI) calcd for $\mathrm{C}_{21} \mathrm{H}_{15} \mathrm{O}_{2} \mathrm{~F}_{3} \mathrm{~S}\left(\mathrm{M}^{+} \cdot\right) \mathrm{m} / 2388.0745$, found 388.0746.

1,3,5-Tris(4-ethenylphenyl)benzene (6). To a stirred solution of 1,3,5-tris(4formylphenyl)benzene ${ }^{[16]}(220 \mathrm{mg}, \quad 0.563 \mathrm{mmol})$ in anhydrous THF $(7.5 \mathrm{~mL})$, methyltriphenylphosphonium iodide $(1.37 \mathrm{~g}, 3.38 \mathrm{mmol})$ and sodium hydride $(135 \mathrm{mg}, 5.63 \mathrm{mmol})$ were added. The solution was stirred for $48 \mathrm{~h}$, filtered on Celite and the solvent was evaporated. The raw product was purified by column chromatography $\left(\mathrm{CH}_{2} \mathrm{Cl}_{2}\right)$ to yield $210 \mathrm{mg}(97 \%)$ of $\mathbf{6}$ as a yellow solid; ${ }^{1} \mathrm{H}$ NMR (200.13 MHz, $\left.\mathrm{CDCl}_{3}\right) \delta 7.79(\mathrm{~s}, 3 \mathrm{H}), 7.68$ and $7.53\left(\mathrm{AA}^{\prime} \mathrm{XX}^{\prime}, J_{\mathrm{AX}}=8.3,12 \mathrm{H}\right), 6.81$ $(\mathrm{dd}, J=17.6,10.9,3 \mathrm{H}), 5.83(\mathrm{~d}, J=17.6,3 \mathrm{H}), 5.31(\mathrm{~d}, J=10.9,3 \mathrm{H}) ;{ }^{13} \mathrm{C}$ NMR $\left(75.47 \mathrm{MHz}, \mathrm{CDCl}_{3}\right)$ 
$\delta 141.9,140.4,136.9,136.4,127.4,126.7,124.8,114.1$; HRMS (EI) calcd for $\mathrm{C}_{30} \mathrm{H}_{24}\left(\mathrm{M}^{+}\right.$) $\mathrm{m} / \mathrm{z}$ 384.1878, found 384.1877 .

\section{1,3,5-Tris[4-[(1E)-2-[4-[(trifluoromethyl)sulfonyl]phenyl]ethenyl]phenyl]benzene}

$\left.\left(\mathbf{T P B}\left[(\mathbf{P V})_{1} \mathbf{S O}_{2} \mathbf{C F}_{3}\right)\right]_{3}\right)$. Air was removed from a solution of 1,3,5-tris(4-ethenylphenyl)benzene (6) (170 mg, $0.442 \mathrm{mmol})$ and 4 (447 mg, $1.547 \mathrm{mmol})$ in anhydrous DMF (4 mL) by blowing argon for $20 \mathrm{~min}$. Then triethylamine (179 $\mathrm{mg}, 1.768 \mathrm{mmol})$, tri-o-tolylphosphine $(40 \mathrm{mg}, 0.133 \mathrm{mmol})$ and palladium diacetate $(17 \mathrm{mg}, 0.066 \mathrm{mmol})$ were added. The mixture was stirred at $100^{\circ} \mathrm{C}$ for $15 \mathrm{~h}$. The solvent was removed by distillation, and the raw product was purified by column chromatography (heptane/ $\mathrm{CH}_{2} \mathrm{Cl}_{2}$ 80:20 then 30:70) to yield $168 \mathrm{mg}$ (38\%) of $\mathbf{T P B}\left[(\mathbf{P V})_{1} \mathbf{S O}_{2} \mathbf{C F}_{3}\right]_{3}$ as a pale yellow solid; ${ }^{1} \mathrm{H}$ NMR (200.13 MHz, $\left.\mathrm{CDCl}_{3}\right) \delta 8.03$ and $7.80\left(\mathrm{AA}^{\prime} \mathrm{XX}\right.$ ', $\left.J_{\mathrm{AX}}=8.6 \mathrm{~Hz}, 12 \mathrm{H}\right), 7.86(\mathrm{~s}, 3 \mathrm{H})$, 7.78 and $7.70\left(\mathrm{AA}^{\prime} \mathrm{XX} X^{\prime}, J_{\mathrm{AX}}=8.6 \mathrm{~Hz}, 12 \mathrm{H}\right), 7.42(\mathrm{~d}, J=16.2 \mathrm{~Hz}, 3 \mathrm{H}), 7.23(\mathrm{~d}, J=16.2 \mathrm{~Hz}, 3 \mathrm{H}) ;{ }^{19} \mathrm{~F}$ NMR $\left(282.38, \mathrm{CDCl}_{3}\right) \delta-78.36$; HRMS $\left(\mathrm{ES}^{+}, \mathrm{MeOH} / \mathrm{CH}_{2} \mathrm{Cl}_{2}\right)$ calcd for $\mathrm{C}_{51} \mathrm{H}_{33} \mathrm{O}_{6} \mathrm{~F}_{9} \mathrm{~S}_{3} \mathrm{~K}\left([\mathrm{M}+\mathrm{K}]^{+}\right)$ $m / z$ 1047.0933, found 1047.0937.

\section{Optical experiments}

UV-vis. UV-vis spectra were recorded on a Jasco V-570 spectrophotometer using spectroscopic grade solvents.

Fluorescence. Steady-state and time resolved fluorescence measurements were performed at room temperature in dilute solutions ( $\left.\mathrm{ca} .10^{-6} \mathrm{M}\right)$ using an Edinburgh Instruments (FLS 920) spectrometer in photon-counting mode. Emission spectra were obtained, for each compound, at $\lambda_{\mathrm{ex}}=\lambda_{\max }$ (abs) with $\mathrm{A}_{\lambda e x} \leq 0.1$ to minimize internal absorption. Fluorescence quantum yields were measured on degassed samples at room temperature; fluorescein in $0.1 \mathrm{~N} \mathrm{NaOH}$ was used as a standard (quantum yield $\Phi=0.90) .{ }^{[31]}$ The lifetime values were obtained from the reconvolution fit analysis of the decay profiles with the F900 analysis software and the fitting results were judged by the reduced chi-square value. The chi-square analysis indicates that $\tau$ values longer than $\sim 0.3 \mathrm{~ns}$ are known with a good confidence (the uncertainty decreasing when $\tau$ increases, and always less than $\sim 10 \%$ ), while very short lifetimes (shorter than the excitation pulse duration) are less reliable. For this reason we mainly concentrate our discussion based on lifetimes on the donor-series, which has well reliable $\tau$ values. 
Two-photon excitation cross-sections of dipolar and octupolar chromophores were determined by investigating their two-photon-excited fluorescence (TPEF) in solution. These measurements provide the TPEF action cross-section $\sigma_{2} \Phi$. The corresponding $\sigma_{2}$ (TPA cross section) values were then obtained by using the fluorescence quantum yield $\Phi$ values derived from standard fluorescence measurements. We emphasize that experiments were conducted in the femtosecond regime thus preventing contribution from excited absorption that is known to lead to artificially enhanced "effective" TPA cross-sections when measurements (in particular nonlinear transmission) are conducted in the nanosecond regime.

TPEF measurements were conducted using a mode-locked Ti:sapphire laser operating between 700 and $990 \mathrm{~nm}$ and delivering $150 \mathrm{fs}$ pulses at $76 \mathrm{MHz}$, following the experimental protocol described in detail by $\mathrm{Xu}$ and Webb. ${ }^{[32]}$ The quadratic dependence of the fluorescence intensity on the excitation intensity was verified for each data point, indicating that the measurements were carried out in intensity regimes in which saturation or photodegradation do not occur. TPEF measurements were calibrated relative to the absolute TPEF action cross-section determined by $\mathrm{Xu}$ and Webb for fluorescein in water $(\mathrm{pH}=11)$ in the $690-1050 \mathrm{~nm}$ range ${ }^{[32,33]}$ Equations for relative determination of $\sigma_{2}$ were adopted as reported in Ref. ${ }^{[34]}$ For solubility reasons TPEF experiments were conducted in toluene for dipolar and octupolar derivatives with $\mathbf{N H e x}_{2}$ end-groups and in DMSO for dipolar and octupolar derivatives bearing $\mathbf{S O}_{\mathbf{2}} \mathbf{C F}_{\mathbf{3}}$ end-groups. These two solvents have very similar refractive index, so that any possible problem linked to refractive index correction for the evaluation of TPA cross section is avoided.

\section{Theoretical modeling}

For the sake of simplicity, hexyl chains of the donor derivatives have been replaced by methyl groups and solvation effects have been neglected. Ground-state optimized geometries have been obtained using the Gaussian 98 package ${ }^{[35]}$ at the Hartree-Fock (HF) level using the 6-31G* basis set. Excited-state geometry optimization has been performed using the TURBOMOLE package ${ }^{[36]}$ at the time dependent HF (TD-HF) level using the all SV basis set. TURBOMOLE was used to calculate all subsequent properties at the TD-B3LYP level of theory with the all SVP basis set. Different basis sets have been tested for both ground-state geometry optimization and properties. These calculations 
revealed the well known sensitivity of dipole moment calculations to basis sets: the problem is especially relevant for permanent dipole moments, while transition dipole moments are much less basis-set dependent. Trends are nevertheless robust and are used to assist interpretation of experimental data.

The nature of the excited states has been investigated through natural transition orbital analysis of the excited states ${ }^{[37]}$ based on the calculated transition densities. Figures showing molecular geometries and transition orbitals have been obtained with XCrySDEN. ${ }^{[38]}$

\section{Acknowledgements}

We acknowledge financial support from Région Bretagne («Renouvellement des Compétences » Program) and Rennes Métropole. FT acknowledges Université de Rennes 1 for an invited assistant professor position. Calculations have been performed at the "Centre Informatique National de l'Enseignement Supérieur" (CINES-France).

[1] R. R. Birge, Acc. Chem. Res. 1986, 19, 138. S. Shima, R. P. Ilagan, N. Gillespie, B. J. Sommer, R. G. Hiller, F. P. Sharples, H. A. Frank, R. R. Birge, J. Phys. Chem. A 2003, 107,8052 .

[2] D. A. Parthenopoulos, P. M. Rentzepis, Science 1989, 245, 843. J. H. Strickler, W. W. Webb, Opt. Lett. 1991, 16, 1780. A. S. Dvornikov, P. M. Rentzepis, Opt. Commun. 1995, 119, 341. K. D. Belfield, K. J. Schafer, Chem. Mater. 2002, 14, 3656. K. D. Belfield, Y. Liu, R. A. Negres, M. Fan, G. Pan, D. J. Hagan, F. E. Hernandez, Chem. Mater. 2002, 14, 3663.

[3] S. Maruo, O. Nakamura, S. Kawata, Opt. Lett. 1997, 22, 132. B. H. Cumpston, S. P. Ananthavel, S. Barlow, D. L. Dyer, J. E. Ehrlich, L. L. Erskine, A. A. Heikal, S. M. Kuebler, I.-Y. S. Lee, D. McCord-Maughon, J. Qin, H. Röckel, M. Rumi, X. L. Wu, S. R. Marder, J. W. Perry, Nature 1999, 398, 51. S. Kawata, H.-B. Sun, T. Tanaka, K. Takada, Nature 2001, 412, 697. W. Zhou, S. M. Kuebler, K. L. Braun, T. Yu, J. K. Cammack, C. K. Ober, J. W. Perry, S. R. Marder, Science 2002, 296, 1106.

[4] J. D. Bhawalkar, G. S. He, C.-K. Park, C. F. Zhao, G. Ruland, P. N. Prasad, Opt. Commun. 1996, 124, 33. A. Abbotto, L. Beverina, R. Bozio, S. Bradamante, C. Ferrante, G. A. Pagani, R. Signorini, Adv. Mater. 2000, 12, 1963.

[5] W. Denk, J. H. Strickler, W. W. Webb, Science 1990, 248, 73. C. Xu, W. Zipfel, J. B. Shear, R. M. Williams, W. W. Webb, Proc. Natl. Acad. Sci. U. S. A. 1996, 93, 10763. W. Denk, P. B. Detwiler, Proc. Natl. Acad. Sci. U. S. A. 1999, 96, 7035. D. R. Larson, W. R. Zipfel, R. M. Williams, S. W. Clark, M. P. Bruchez, F. W. Wise, W. W. Webb, Science 2003, 300, 1434.

[6] J. D. Bhawalkar, N. D. Kumar, C. F. Zhao, P. N. Prasad, J. Clin. Laser Med. Surg. 1997, 15, 201. P. K. Frederiksen, M. Jørgensen, P. R. Ogilby, J. Am. Chem. Soc. 2001, $123,1215$. 
[7] S. R. Marder, D. N. Beratan, L. T. Cheng, Science 1991, 252, 103. D. R. Kanis, M. A. Ratner, T. J. Marks, Chem. Rev. 1994, 94, 195. J.-L. Brédas, K. Cornil, F. Meyers, D. Beljonne, in Handbook of Conducting Polymers, Vol. 1 (Eds.: T. A. Skotheim, R. L. Elsenbaumer, J. R. Reynolds), Marcel Dekker, New York, 1998, pp. 1.

[8] W. Verbouwe, L. Viaene, M. Van der Auweraer, F. C. De Schryver, H. Masuhara, R. Pansu, J. Faure, J. Phys. Chem. A 1997, 101, 8157.

[9] M. Albota, D. Beljonne, J.-L. Brédas, J. E. Ehrlich, J.-Y. Fu, A. A. Heikal, S. E. Hess, T. Kogej, M. D. Levin, S. R. Marder, D. McCord-Maughon, J. W. Perry, H. Röckel, M. Rumi, G. Subramaniam, W. W. Webb, X.-L. Wu, C. Xu, Science 1998, 281, 1653. K. D. Belfield, D. J. Hagan, E. W. Van Stryland, K. J. Schafer, R. A. Negres, Org. Lett. 1999, 1, 1575. L. Ventelon, M. Blanchard-Desce, L. Moreaux, J. Mertz, Chem. Commun. 1999, 2055. M. Rumi, J. E. Ehrlich, A. A. Heikal, J. W. Perry, S. Barlow, Z.Y. Hu, D. McCord-Maughon, T. C. Parker, H. Röckel, S. Thayumanavan, S. R. Marder, D. Beljonne, J.-L. Brédas, J. Am. Chem. Soc. 2000, 122, 9500. S. J. K. Pond, M. Rumi, M. D. Levin, T. C. Parker, D. Beljonne, M. W. Day, J.-L. Brédas, S. R. Marder, J. W. Perry, J. Phys. Chem. A 2002, 106, 11470. D. Scherer, R. Dörfler, A. Feldner, T. Vogtmann, M. Schwoerer, U. Lawrentz, W. Grahn, C. Lambert, Chem. Phys. 2002, 279, 179. L. Antonov, K. Kamada, K. Ohta, F. S. Kamounah, Phys. Chem. Chem. Phys. 2003, 5, 1193. B. Strehmel, A. M. Sarker, H. Detert, ChemPhysChem 2003, 4, 249. W. J. Yang, D. Y. Kim, M.-Y. Jeong, H. M. Kim, S.-J. Jeon, B. R. Cho, Chem. Commun. 2003, 2618. M. H. V. Werts, S. Gmouh, O. Mongin, T. Pons, M. Blanchard-Desce, J. Am. Chem. Soc. 2004, 126, 16294. E. Zojer, W. Wenseleers, P. Pacher, S. Barlow, M. Halik, C. Grasso, J. W. Perry, S. R. Marder, J.-L. Brédas, J. Phys. Chem. B 2004, 108, 8641. H. Y. Woo, B. Liu, B. Kohler, D. Korystov, A. Mikhailovsky, G. C. Bazan, J. Am. Chem. Soc. 2005, 127, 14721. S. Amthor, C. Lambert, S. Duemmler, I. Fischer, J. Schelter, J. Phys. Chem. A 2006, 110, 5204.

[10] C. Katan, F. Terenziani, O. Mongin, M. H. V. Werts, L. Porrès, T. Pons, J. Mertz, S. Tretiak, M. Blanchard-Desce, J. Phys. Chem. A 2005, 109, 3024.

[11] G. Verbeek, S. Depaemelaere, M. Van der Auweraer, F. C. De Schryver, A. Vaes, D. Terrell, S. De Meutter, Chem. Phys. 1993, 176, 195. S. Stadler, F. Feiner, C. Bräuchle, S. Brandl, R. Gompper, Chem. Phys. Lett. 1995, 245, 292. W. Verbouwe, M. Van der Auweraer, F. C. De Schryver, J. J. Piet, J. M. Warman, J. Am. Chem. Soc. 1998, 120, 1319. S.-J. Chung, K.-S. Kim, T.-C. Lin, G. S. He, J. Swiatkiewicz, P. N. Prasad, J. Phys. Chem. B 1999, 103, 10741. C. Lambert, W. Gaschler, E. Schmälzlin, K. Meerholz, C. Bräuchle, J. Chem. Soc., Perkin Trans. 2 1999, 2, 577. B. R. Cho, S. J. Lee, S. H. Lee, K. H. Son, Y. H. Kim, J.-Y. Doo, G. J. Lee, T. I. Kang, Y. K. Lee, M. Cho, S.-J. Jeon, Chem. Mater. 2001, 13, 1438. S.-J. Chung, T.-C. Lin, K.-S. Kim, G. S. He, J. Swiatkiewicz, P. N. Prasad, G. A. Baker, F. V. Bright, Chem. Mater. 2001, 13, 4071. A. Abbotto, L. Beverina, R. Bozio, A. Facchetti, C. Ferrante, G. A. Pagani, D. Pedron, R. Signorini, Chem. Commun. 2003, 2144. O. Mongin, L. Porrès, C. Katan, T. Pons, J. Mertz, M. Blanchard-Desce, Tetrahedron Lett. 2003, 44, 8121. H. J. Lee, J. Sohn, J. Hwang, S. Y. Park, H. Choi, M. Cha, Chem. Mater. 2004, 16, 456. S. A. Lahankar, R. West, O. Varnavski, X. Xie, T. Goodson III, J. Chem. Phys. 2004, 120, 337. F. Meng, B. Li, S. Qian, K. Chen, H. Tian, Chem. Lett. 2004, 33, 470. L. Porrès, O. Mongin, C. Katan, M. Charlot, T. Pons, J. Mertz, M. Blanchard-Desce, Org. Lett. 2004, 6, 47. P. R. Bangal, D. M. K. Lam, L. A. Peteanu, M. Van der Auweraer, J. Phys. Chem. $B$ 2004, 108, 16834.

[12] B. R. Cho, K. H. Son, H. L. Sang, Y.-S. Song, Y.-K. Lee, S.-J. Jeon, J. H. Choi, H. Lee, M. Cho, J. Am. Chem. Soc. 2001, 123, 10039.

[13] W.-H. Lee, H. Lee, J.-A. Kim, J.-H. Choi, M. Cho, S.-J. Jeon, B. R. Cho, J. Am. Chem. Soc. 2001, 123, 10658.

[14] D. Beljonne, W. Wenseleers, E. Zojer, Z. Shuai, H. Vogel, S. J. K. Pond, J. W. Perry, S. R. Marder, J.-L. Brédas, Adv. Funct. Mater. 2002, 12, 631. 
[15] O. P. Varnavski, J. C. Ostrowski, L. Sukhomlinova, R. J. Twieg, G. Bazan, C., T. Goodson III, J. Am. Chem. Soc. 2002, 124, 1736. L. A. Liu, L. A. Peteanu, D. J. Yaron, J. Phys. Chem. B 2004, 108, 16841.

[16] J. Brunel, O. Mongin, A. Jutand, I. Ledoux, J. Zyss, M. Blanchard-Desce, Chem. Mater. 2003, 15, 4139 .

[17] C. Le Droumaguet, O. Mongin, M. H. V. Werts, M. Blanchard-Desce, Chem. Commun. 2005, 2802.

[18] T. G. Goodson III, Acc. Chem. Res. 2005, 38, 99.

[19] Y. Wang, G. S. He, P. N. Prasad, T. Goodson III, J. Am. Chem. Soc. 2005, 127, 10128.

[20] A. Adronov, J. M. J. Fréchet, G. S. He, K.-S. Kim, S.-J. Chung, J. Swiatkiewicz, P. N. Prasad, Chem. Mater. 2000, 12, 2838. H. Meier, M. Lehmann, U. Kolb, Chem. Eur. J. 2000, 6, 2462. E. Díez-Barra, J. C. García-Martínez, S. Merino, R. del Rey, J. Rodríguez-López, P. Sánchez-Verdú, J. Tejeda, J. Org. Chem. 2001, 66, 5664. M. Drobizhev, A. Karotki, A. Rebane, C. W. Spangler, Opt. Lett. 2001, 26, 1081. H. Ma, A. K.-Y. Jen, Adv. Mater. 2001, 13, 1201. J. L. Segura, R. Gómez, N. Martín, D. M. Guldi, Org. Lett. 2001, 3, 2645. M. I. Ranasinghe, O. P. Varnavski, J. Pawlas, S. I. Hauck, J. Louie, J. F. Hartwig, T. Goodson, III, J. Am. Chem. Soc. 2002, 124, 6520. M. Drobizhev, A. Karotki, Y. Dzenis, A. Rebane, Z. Suo, C. W. Spangler, J. Phys. Chem. B 2003, 107, 7540. O. Mongin, J. Brunel, L. Porrès, M. Blanchard-Desce, Tetrahedron Lett. 2003, 44, 2813. K. M. Gaab, A. L. Thompson, J. Xu, T. J. Martínez, C. J. Bardeen, J. Am. Chem. Soc. 2003, 125, 9288. C. W. Spangler, Z. Suo, M. Drobizhev, A. Karotki, A. Rebane, NATO Sci. Ser., II Math. Phys. Chem. 2003, 100, 139. Y. Wang, M. I. Ranasinghe, T. Goodson, III, J. Am. Chem. Soc. 2003, 125, 9562. D. W. Brousmiche, J. M. Serin, J. M. J. Fréchet, G. S. He, T.-C. Lin, S.-J. Chung, P. N. Prasad, R. Kannan, L.-S. Tan, J. Phys. Chem. B 2004, 108, 8592. A. L. Thompson, K. M. Gaab, J. Xu, C. J. Bardeen, T. J. Martínez, J. Phys. Chem. A 2004, 108, 671. O. Mongin, T. Rama Krishna, M. H. V. Werts, A.-M. Caminade, J.-P. Majoral, M. Blanchard-Desce, Chem. Commun. 2006, 915.

[21] L. C. T. Shoute, G. P. Bartholomew, G. C. Bazan, A. Myers Kelley, J. Chem. Phys. 2005, 122, 184508. T.-C. Lin, G. S. He, Q. Zheng, P. N. Prasad, J. Mater. Chem. 2006, 16, 2490. P. Macak, Y. Luo, P. Norman, H. Ågren, J. Chem. Phys. 2000, 113, 7055.

[22] C. Katan, F. Terenziani, C. L. Droumaguet, O. Mongin, M. H. V. Werts, S. Tretiak, M. Blanchard-Desce, Proc. SPIE-Int. Soc. Opt. Eng. 2005, 5935, 593503.

[23] W. J. Yang, D. Y. Kim, C. H. Kim, M.-Y. Jeong, S. K. Lee, S.-J. Jeon, B. R. Cho, Org. Lett. 2004, 6, 1389.

[24] A. Myers Kelley, L. C. T. Shoute, M. Blanchard-Desce, G. P. Bartholomew, G. Bazan, Mol. Phys. 2006, 104, 1239.

[25] S. J. Strickler, R. A. Berg, J. Chem. Phys. 1962, 37, 814.

[26] J.-L. Brédas, J. Cornil, D. Beljonne, D. A. Dos Santos, Z. Shuai, Acc. Chem. Res. 1999, 32, 267. S. Tretiak, A. Saxena, R. L. Martin, A. R. Bishop, Phys. Rev. Lett. 2002, 89, 097402.

[27] E. Lippert, Z. Naturforsch. A 1955, 10, 541. N. Mataga, Y. Kaifu, M. Koizumi, Bull. Chem. Soc. Jpn. 1955, 28, 690.

[28] A. S. Davidov, Theory of molecular excitons, Plenum Press, New York, 1971. E. A. Silinsh, V. Capek, Organic Molecular Crystals: Interaction, Localization, and Transport Phenomena, AIP Press, New York, 1994.

[29] L. Porrès, B. K. G. Bhatthula, M. Blanchard-Desce, Synthesis 2003, 1541.

[30] G. Wulff, P. K. Dhal, Macromolecules 1990, 23, 100.

[31] J. N. Demas, G. A. Crosby, J. Phys. Chem. 1971, 75, 991.

[32] C. Xu, W. W. Webb, J. Opt. Soc. Am. B 1996, 13, 481. 
[33] M. A. Albota, C. Xu, W. W. Webb, Appl. Opt. 1998, 37, 7352.

[34] M. H. V. Werts, N. Nerambourg, D. Pélégry, Y. L. Grand, M. Blanchard-Desce, Photochem. Photobiol. Sci. 2005, 4, 531.

[35] Gaussian 98, Revision A.11; Frisch, M. J.; Trucks, G. W.; Schlegel, H. B.; Scuseria, G. E.; Robb, M. A.; Cheeseman, J. R.; Zakrzewski, V. G.; Montgomery Jr., J. A.; Stratmann, R. E.; Burant, J. C.; Dapprich, S.; Millam, J. M.; Daniels, A. D.; Kudin, K. N.; Strain, M. C.; Farkas, O.; Tomasi, J.; Barone, V.; Cossi, M.; Cammi, R.; Mennucci, B.; Pomelli, C.; Adamo, C.; Clifford, S.; Ochterski, J.; Petersson, G. A.; Ayala, P. Y.; Cui, Q.; Morokuma, K.; Malick, D. K.; Rabuck, A. D.; Raghavachari, K.; Foresman, J. B.; Cioslowski, J.; Ortiz, J. V.; Stefanov, B. B.; Liu, G.; Liashenko, A.; Piskorz, P.; Komaromi, I.; Gomperts, R.; Martin, R. L.; Fox, D. J.; Keith, T.; Al-Laham, M. A.; Peng, C. Y.; Nanayakkara, A.; Gonzalez, C.; Challacombe, M.; Gill, P. M. W.; Johnson, B.; Chen, W.; Wong, M. W.; Andres, J. L.; Head-Gordon, M.; S., R. E.; Pople, J. A.; Gaussian, Inc., Pittsburgh PA, 2001.

[36] R. Ahlrichs, M. Bär, M. Häser, H. Horn, C. Kölmel, Chem. Phys. Lett. 1989, 162, 165.

[37] R. L. Martin, J. Chem. Phys. 2003, 118, 4775.

[38] A. Kokalj, J. Mol. Graphics Mod. 1999, 17, 176.

Received: ((will be filled in by the editorial staff))

Published online on ((will be filled in by the editorial staff))

((scheme legends)

((figure legends)) 
Table 1. Photophysical properties of three-branched octupolar chromophores derived from the triphenylbenzene (TPB) core and of their 1-D dipolar analogues bearing a biphenyl (BP) terminal moiety (in toluene).

\begin{tabular}{|c|c|c|c|c|c|c|c|c|c|c|c|}
\hline & $\begin{array}{l}\lambda_{\mathrm{abs}} \\
(\mathrm{nm})\end{array}$ & $\begin{array}{c}\varepsilon \\
\left(10^{3} \mathrm{M}^{-1} \cdot \mathrm{cm}^{-1}\right)\end{array}$ & $\begin{array}{l}\mu_{g e} \\
\text { (D) }\end{array}$ & $\begin{array}{c}\lambda_{\mathrm{em}} \\
(\mathrm{nm})\end{array}$ & $\begin{array}{l}\text { Stokes shift } \\
\left(10^{3} \mathrm{~cm}^{-1}\right)^{b}\end{array}$ & $\Phi^{b}$ & $\begin{array}{c}\tau \\
(\mathrm{ns})^{d}\end{array}$ & $\begin{array}{c}\tau_{0} \\
(\mathrm{~ns})^{e}\end{array}$ & $\begin{array}{c}k_{r} \\
\left(10^{9} \mathrm{~s}^{-1}\right)^{f}\end{array}$ & $\begin{array}{c}k_{n r} \\
\left(10^{9} \mathrm{~s}^{-1}\right)^{g}\end{array}$ & $\begin{array}{c}\text { Slope } \\
\left(10^{3} \mathrm{~cm}^{-1}\right)^{h}\end{array}$ \\
\hline $\mathrm{BP}(\mathrm{PV})_{1} \mathrm{SO}_{2} \mathrm{CF}_{3}$ & 351 & $37(38)^{a}$ & 8 & 424 & 4.91 & 0.04 & 0.19 & 4.52 & 0.22 & 5.04 & 7.7 \\
\hline $\mathrm{TPB}\left[(\mathrm{PV})_{1} \mathrm{SO}_{2} \mathrm{CF}_{3}\right]_{3}$ & 355 & $116(132)^{a}$ & 14 & 420 & 4.33 & 0.10 & 0.17 & 1.72 & 0.58 & 5.30 & 6.6 \\
\hline $\mathbf{B P}(\mathbf{P V})_{1} \mathrm{NHex}_{2}$ & 378 & 44 & 9 & 435 & 3.47 & 0.11 & 0.37 & 3.36 & 0.30 & 2.41 & 10.4 \\
\hline $\mathrm{TPB}\left[(\mathrm{PV})_{1} \mathrm{NHex}_{2}\right]_{3}$ & 384 & 131 & 15 & 438 & 3.21 & 0.36 & 0.63 & 1.75 & 0.57 & 1.02 & 9.7 \\
\hline $\mathrm{TPB}\left[(\mathrm{PV})_{2} \mathrm{NHex}_{2}\right]_{3}$ & 412 & 159 & 16 & 477 & 3.34 & 0.82 & 1.08 & 1.32 & 0.76 & 0.17 & 16.7 \\
\hline \multicolumn{12}{|c|}{$\begin{array}{l}{ }^{a} \text { In DMSO. }{ }^{b} \text { Stokes-shift }=\left(1 / \lambda_{\mathrm{abs}}-1 / \lambda_{\mathrm{em}}\right) \cdot{ }^{c} \text { Fluorescence quantum yield in toluene determined using fluorescein in } 0.1 \mathrm{~N} \mathrm{NaOH} \text { as a standard. } \\
{ }^{d} \text { Experimental fluorescence lifetime measured by TCSPC. }{ }^{e} \text { Radiative excited-state lifetime }\left(\tau_{0}=\tau / \Phi\right) .{ }^{f} \text { Radiative decay rate. }{ }^{g} \text { Non-radiative decay } \\
\text { rate. }{ }^{h} \text { Slope derived from the linear dependence of the Stokes-shift on the polarity-polarizability function of the solvent }\left(\Delta f=(\varepsilon-1) /(2 \varepsilon+1)-\left(n^{2}-\right.\right. \\
\left.1) /\left(2 n^{2}+1\right) \text { where } \varepsilon \text { is the dielectric constant and } n \text { the refractive index }\right) .\end{array}$} \\
\hline
\end{tabular}


Scheme 1. Synthesis of dipolar and octupolar chromophore.

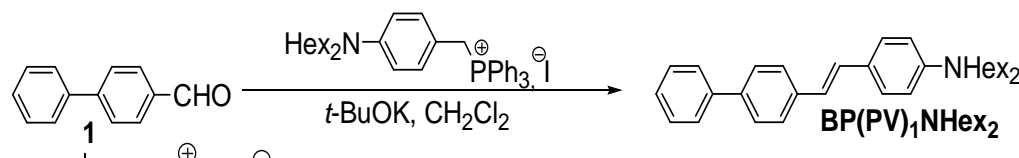

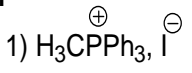

2) $\mathrm{NaH}, \mathrm{THF}$
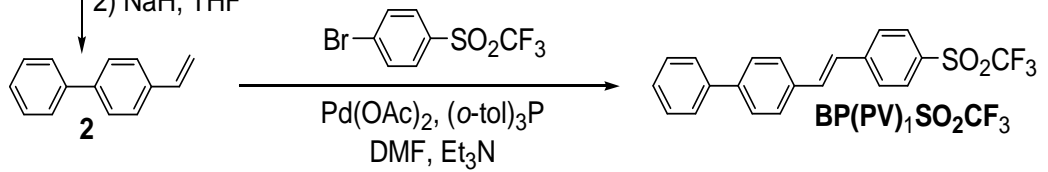

$\mathrm{DMF}, \mathrm{Et}_{3} \mathrm{~N}$

$\mathrm{BP}(\mathrm{PV})_{1} \mathrm{SO}_{2} \mathrm{CF}_{3} \quad \mathrm{SO}_{2} \mathrm{CF}_{3}$

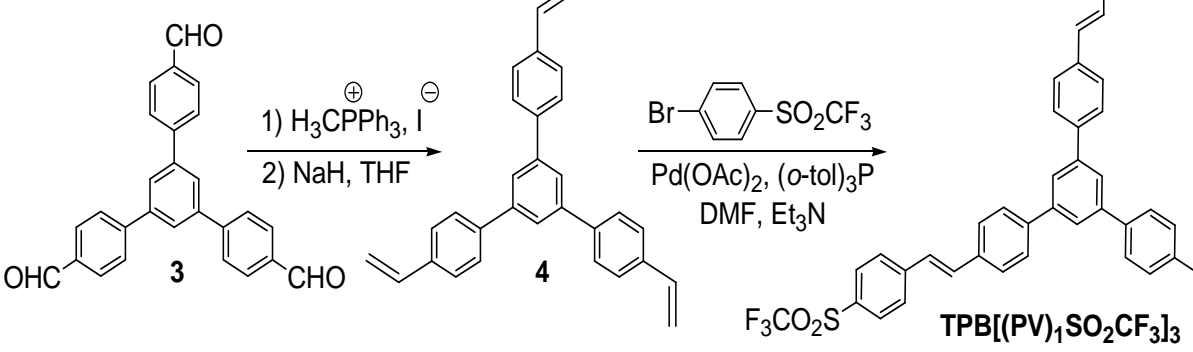

$\mathrm{TPB}\left[(\mathrm{PV})_{1} \mathrm{SO}_{2} \mathrm{CF}_{3}\right]_{3}$

$\mathrm{SO}_{2} \mathrm{CF}_{3}$

23 

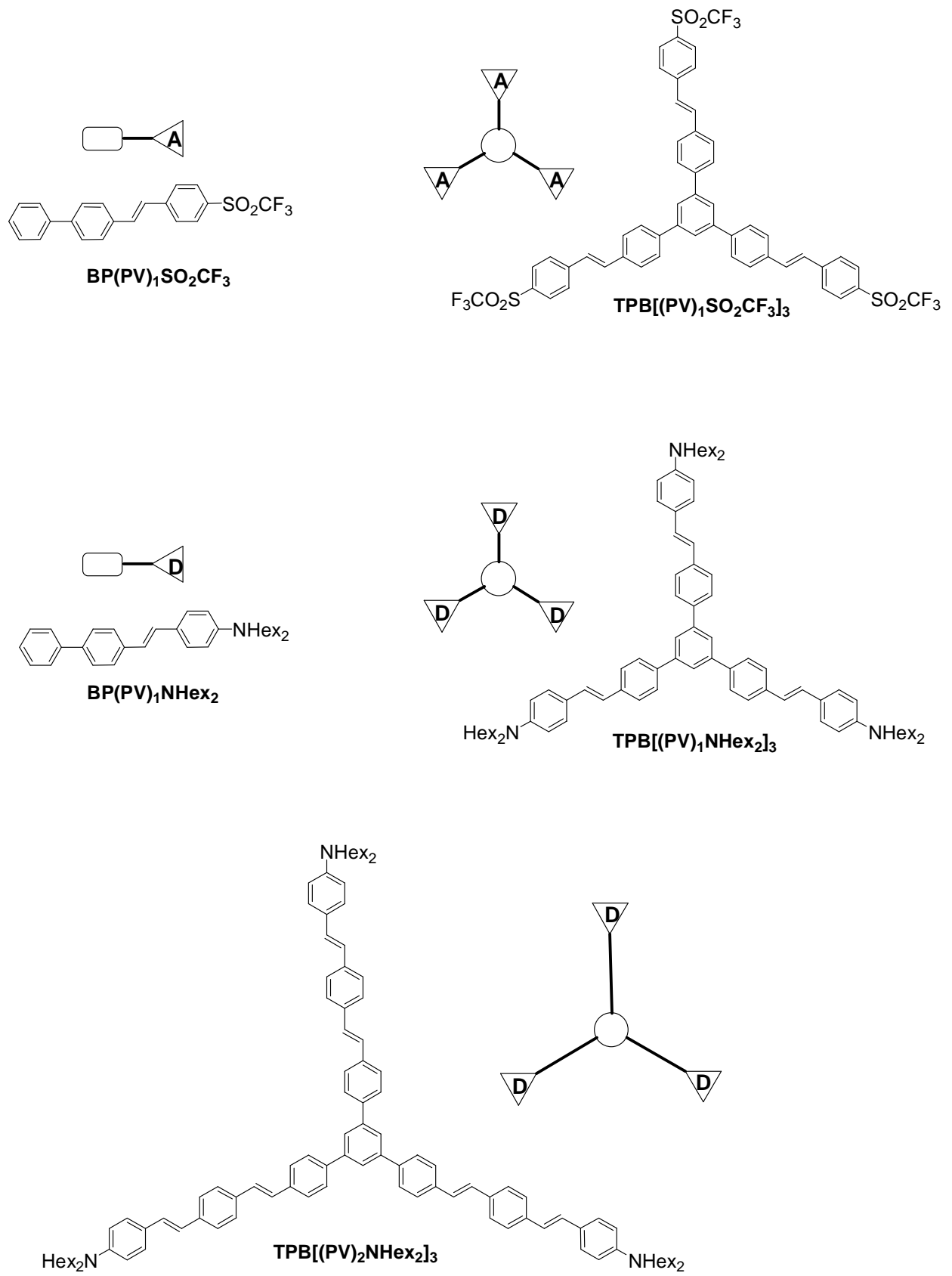

Figure 1. Structure of three-branched octupolar chromophores derived from the triphenylbenzene (TPB) core and their 1-D dipolar analogues bearing a biphenyl (BP) terminal moiety. 

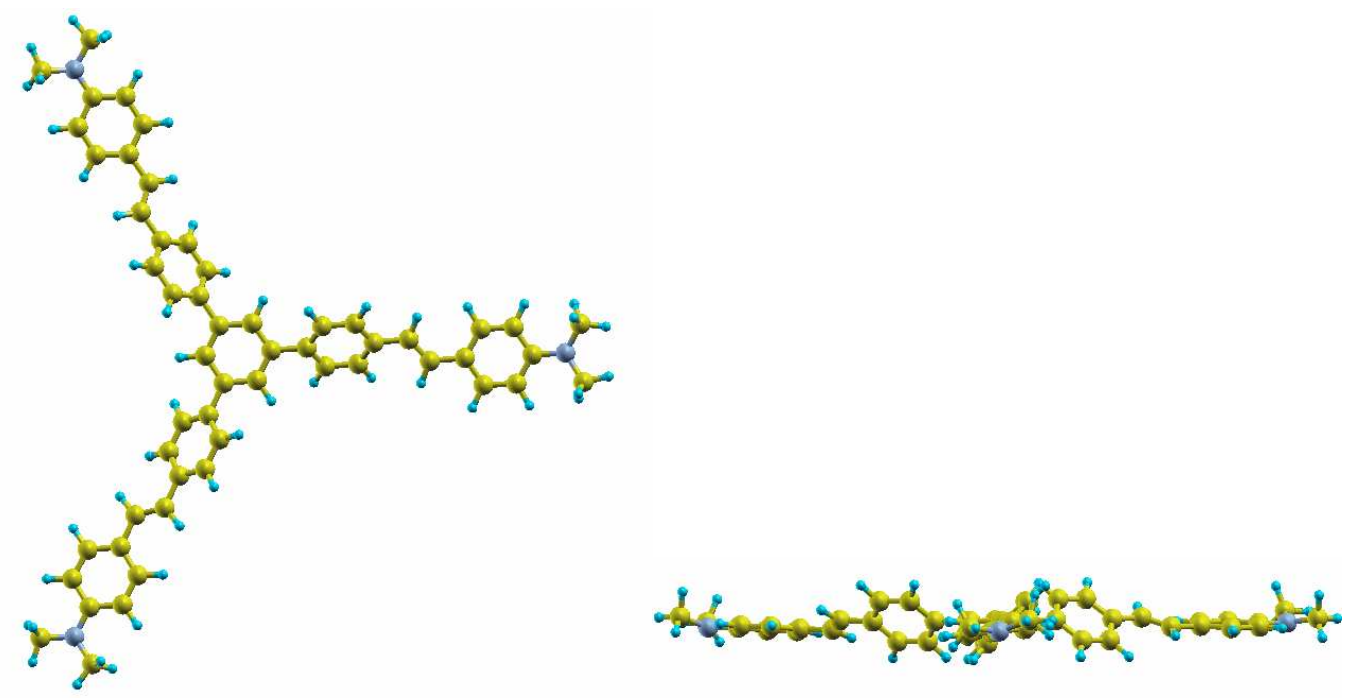

Figure 2. Ground-state optimized geometry of $\mathbf{T P B}\left[(\mathbf{P V})_{\mathbf{1}} \mathbf{N H e x}_{2}\right]_{3}$. 


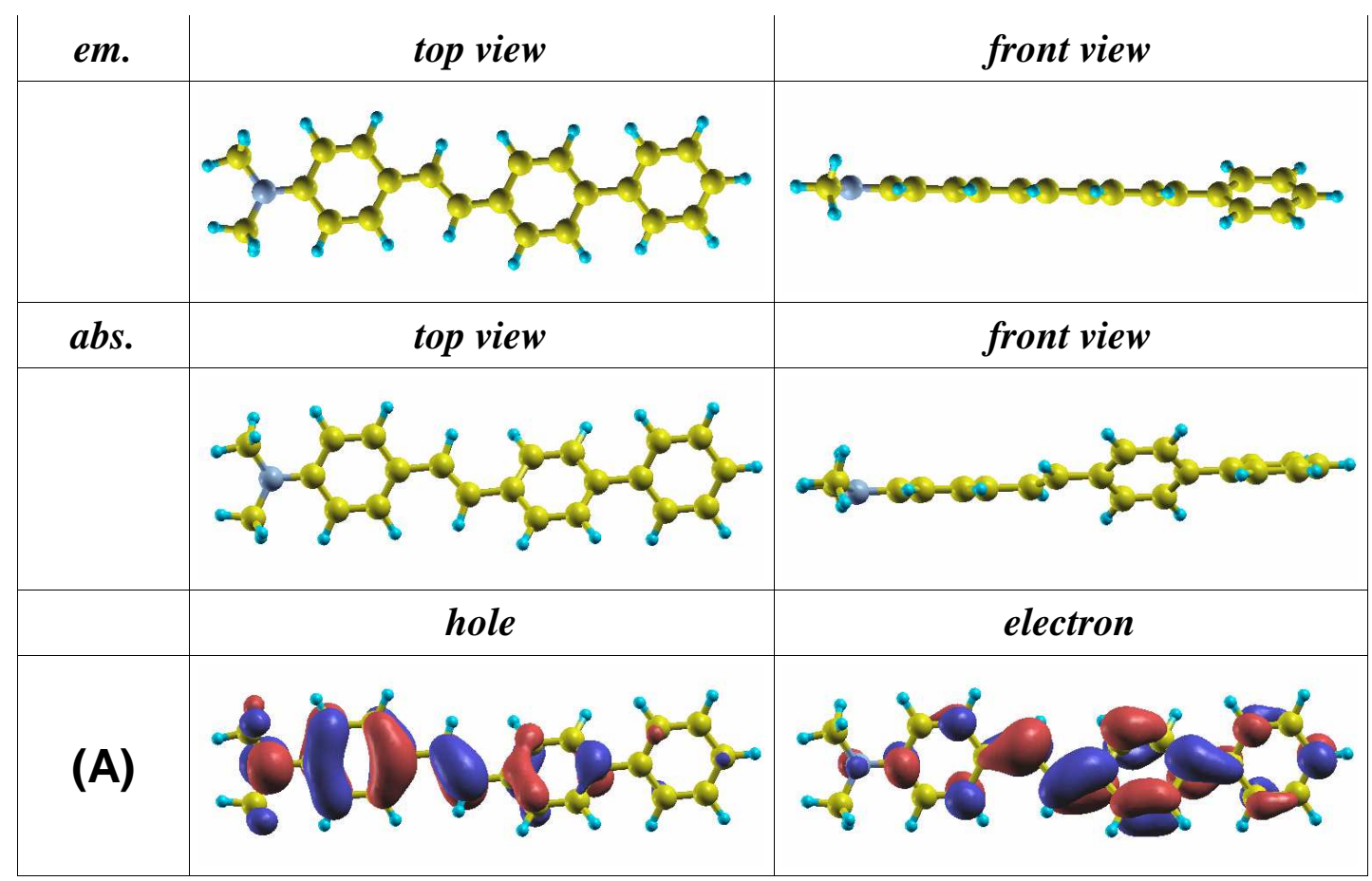

\begin{tabular}{|l|c|c|c|}
\hline em. & front view \\
\hline abs. & top view & front view \\
\hline (B) & hole & \\
\hline & &
\end{tabular}

Figure 3. Calculated geometries and transition orbitals of dipolar chromophores bearing a biphenyl terminal moiety: (A) $\mathbf{B P}(\mathbf{P V})_{\mathbf{1}} \mathbf{N H e x}_{\mathbf{2}}$ and (B) $\mathbf{B P}(\mathbf{P V})_{\mathbf{1}} \mathbf{S O}_{\mathbf{2}} \mathbf{C F}_{\mathbf{3}}$. Excited-state (top panels) and ground-state (mid panels) optimized geometries and corresponding natural transition orbitals (bottom panels). 

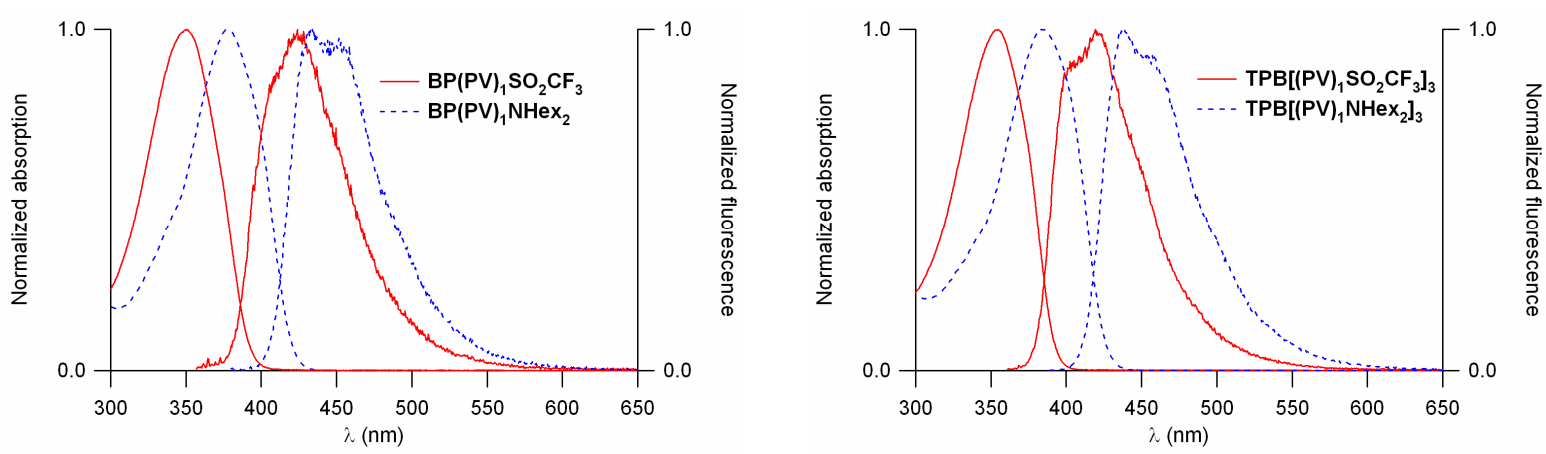

Figure 4. Comparison of absorption and emission spectra of dipolar (left) or octupolar (right) chromophores bearing donor or acceptor end-groups (in toluene).
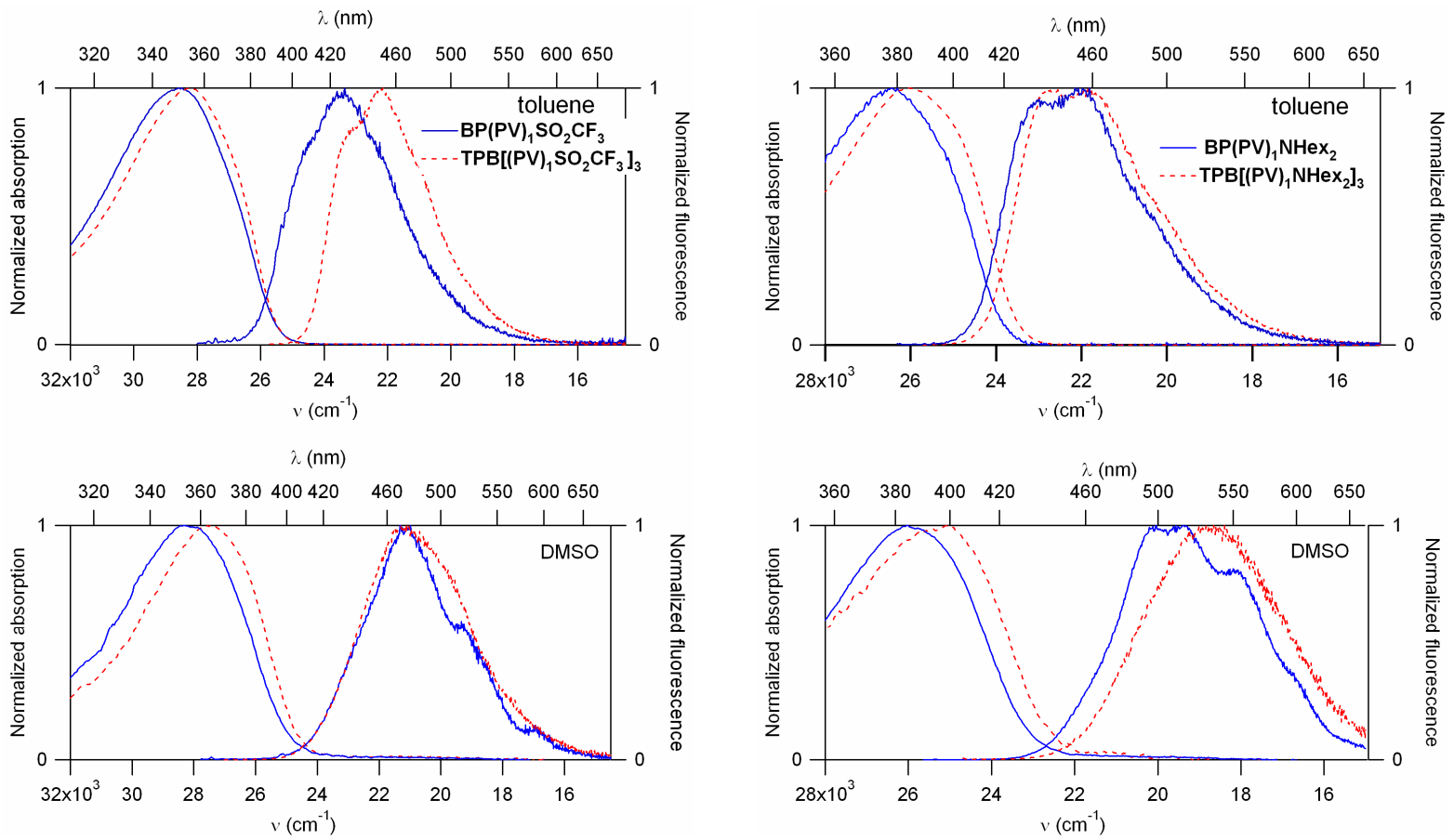

Figure 5. Comparison of absorption and emission spectra of dipolar and octupolar chromophores bearing acceptor end-groups (left), or donor end-groups (right) in toluene (top) and in DMSO (bottom). 

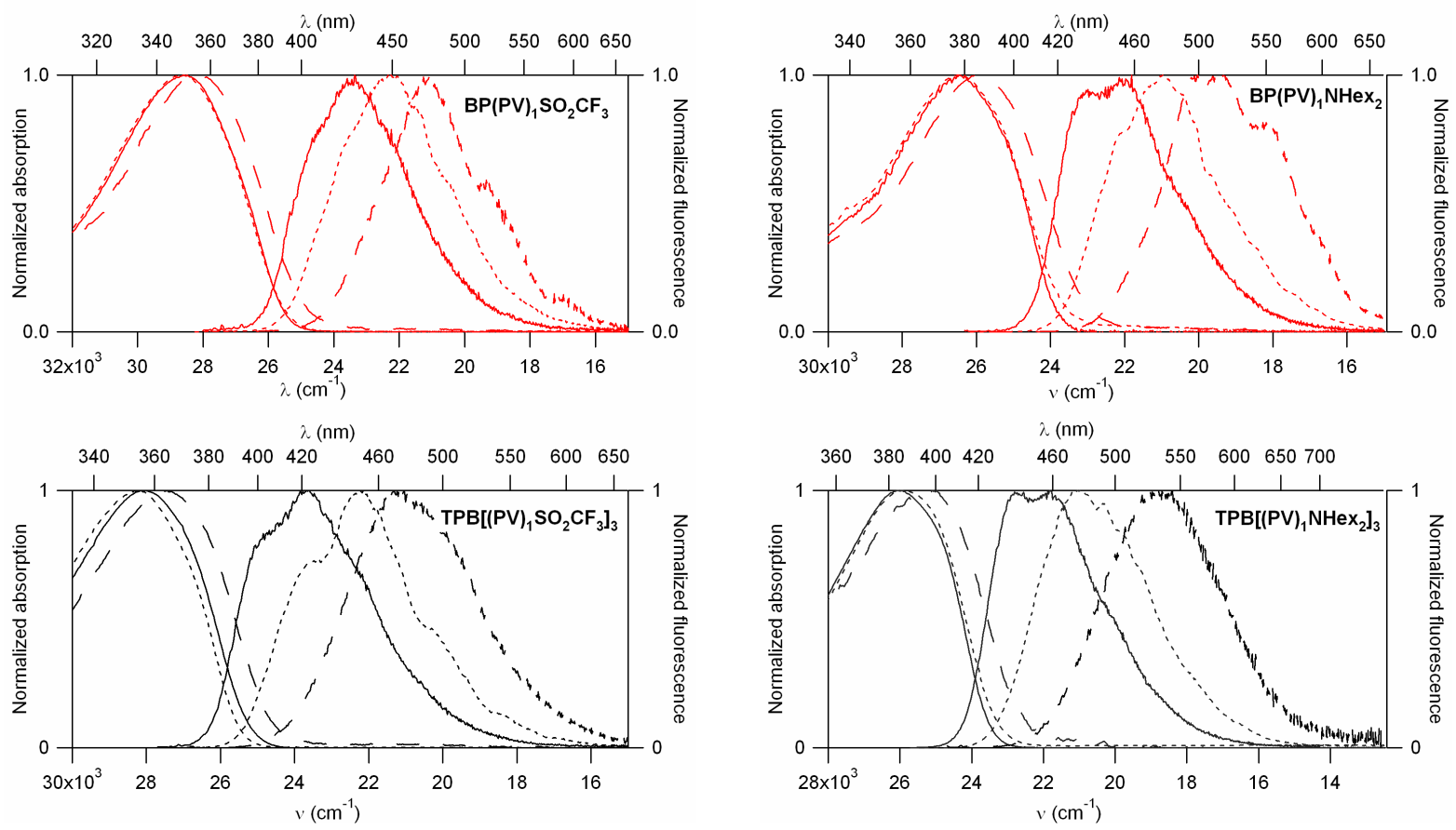

Figure 6. Absorption and emission spectra of dipolar and octupolar studied chromophores in different solvents : in toluene (-), in THF (...) and in DMSO (- - -).
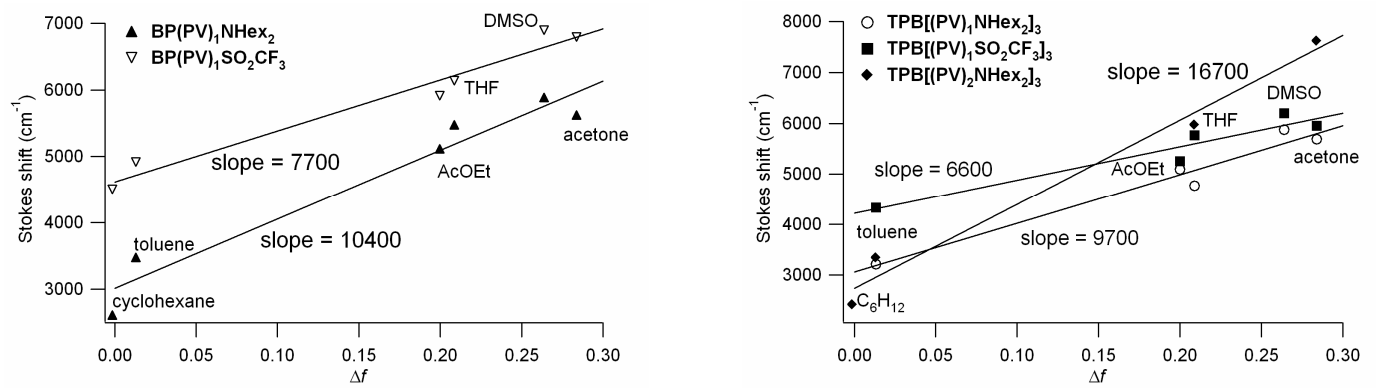

Figure 7. Lippert-Mataga correlations for dipolar (left), and octupolar (right) chromophores. 

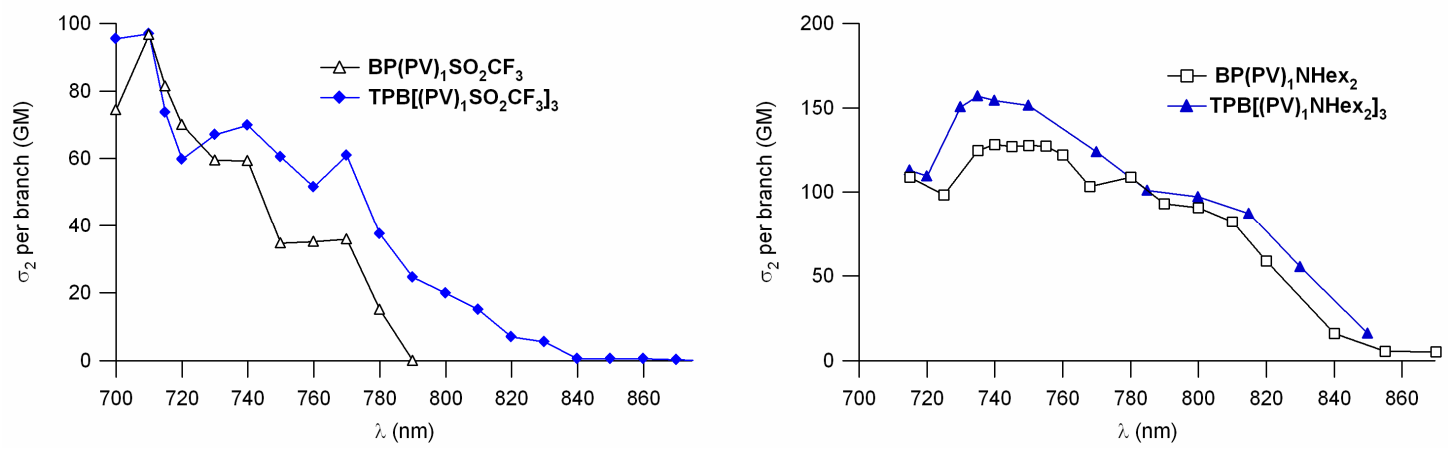

Figure 8. TPA spectra of $\mathbf{B P}(\mathrm{PV})_{1} \mathrm{SO}_{2} \mathrm{CF}_{3}$ and $\mathrm{TPB}\left[(\mathrm{PV})_{1} \mathrm{SO}_{2} \mathrm{CF}_{3}\right]_{3}$ in DMSO (left); $\mathbf{B P}(\mathbf{P V})_{\mathbf{1}} \mathbf{N H e x}_{\mathbf{2}}$ and $\mathbf{T P B}\left[(\mathbf{P V})_{\mathbf{1}} \mathbf{N e x}_{2}\right]_{3}$ in toluene (right).

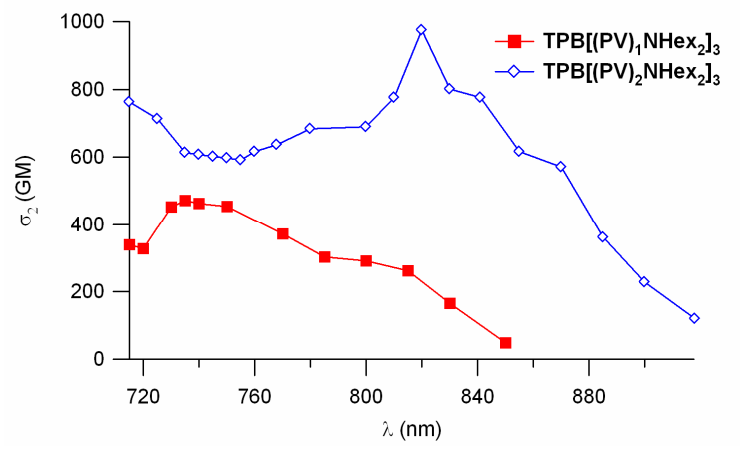

Figure 9. TPA spectra of $\mathbf{T P B}\left[(\mathbf{P V})_{1} \mathrm{NHex}_{2}\right]_{3}$ and $\mathbf{T P B}\left[(\mathbf{P V})_{2} \mathrm{NHex}_{2}\right]_{3}$ : length effect. 


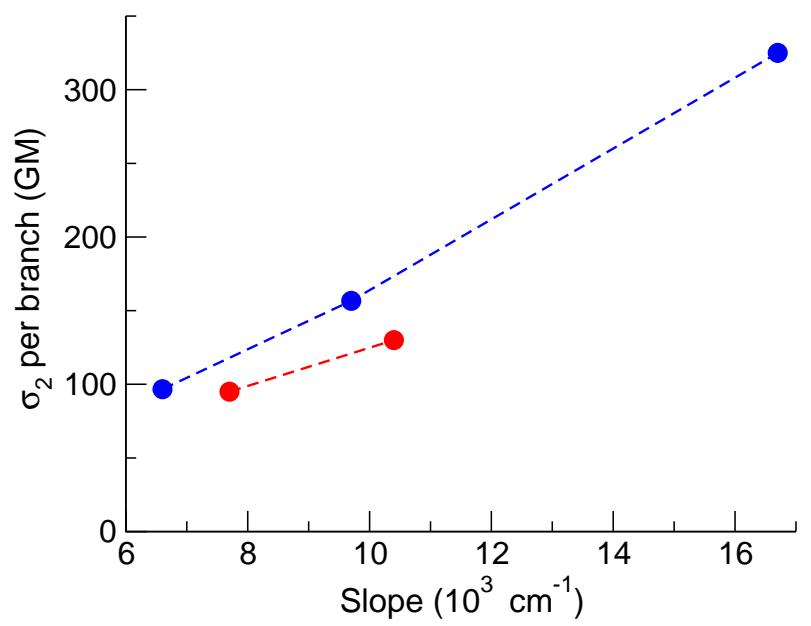

Figure 10. Correlation between maximum TPA cross-section amplitudes and solvatochromic behavior for dipolar (red line) and octupolar (blue line) chromophores. 
Table of contents graphic

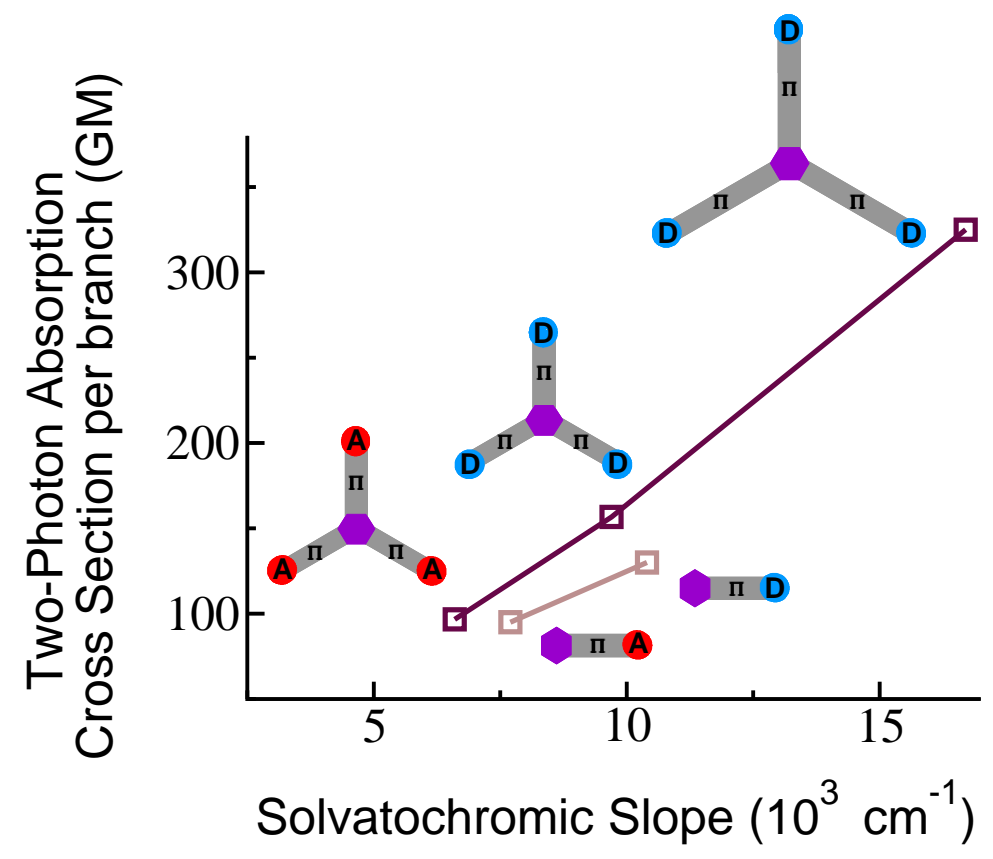

